\section{Berliner Theaterbriefe}

Keller und Hermann Hettner (1821-1882), den Keller an der Universität in Heidelberg kennengelernt hatte, eröffneten ihre Korrespondenz nach Kellers Umzug nach Berlin mit zwei außerordentlichen Briefen: Keller berichtete in einem 8-seitigen Brief über Theaterstücke, über gelesene Bücher und eine Kunstaustellung, die er offenbar zuerst journalistisch hatte besprechen wollen (29.5.1850; GB 1, 313-322). Dieser Brief erfüllt, wie kein anderer Brief Kellers, den Informationsanspruch einer umfassenden privaten Kulturkorrespondenz. Hettner bezeichnete ihn als eine »wahre Pandorabüchse" und schlug in seiner Antwort einen Briefkontrakt vor (21.6.1850; GB 1, 322-329, hier 322 und $325 \mathrm{f}$.): Keller solle seine Korrespondenz aus Berlin fortsetzen und damit beitragen zu einer akademischen Schrift, die er, Hettner, über die Poetik des modernen Dramas zu schreiben beabsichtige. Schon im Oktober 1850 erschien dann, als geschichtlich ausgreifender Vorlauf, eine Artikelserie Hettners mit der Überschrift Die altfranzösische Komödie. An einen Freund in Berlin. Dieser Zeitungstext ist in Briefform gekleidet und beginnt mit den Worten: »Tausend Dank, mein lieber Freund, für Ihre freundlichen Mitteilungen, durch die Sie mich so lebendig an Ihren Berliner Erlebnissen und Kunstgenüssen teilnehmen lassen «. Darauf folgt ein absatzlanges Zitat aus Kellers Brief vom 16. September 1850, in dem Keller, ausgehend von der französischen Schauspielerin Rachel Félix und ihren Berliner Auftritten in Racine-Stücken, kritisch Stellung nimmt zu der in Deutschland verbreiteten oberflächlichen Ablehnung der klassischen französischen Tragödie (GB 1, 329-336, hier 330332). $\mathrm{Zu}$ der für Briefkontrakte typischen Rollenzuweisung und der damit einhergehenden Teil-Fiktionalisierung des Briefpartners - aus Keller wird ein nicht namentlich genannter "Freund in Berlin« kommt in diesem Fall hinzu: Die von Hettner verwendete literarische Publikationsform des (fiktiven) Briefes macht die öffentliche Publikation zugleich zu einem Teil einer realen Privatkorrespondenz.

Als dann 1852 die auf das zeitgenössische Theatergeschehen gerichtete Schrift Das moderne Drama. Ästhetische Untersuchung von Hermann Hettner erschien (vgl. dazu 15, 484 f.), wiederholte sich die Verwendung von Keller-Zitaten in Hettners Schriften.

Der zugrundeliegende Briefkontrakt gehörte zu einem ausgeklügelten und weit darüber hinaus ausgedehnten System der gegenseitigen Unterstützung und Förderung (s. Kap. IV.B.57.1). Dazu zählen u. a. auch verabredete taktische Rezensionen, z. B. Kellers Besprechung von Hettners Das moderne Drama (Keller 1852) oder Hettners Besprechung von Kellers Grünem Heinrich (National-Zeitung, Nr. 209, 5.5.1854).

Keller verhält sich in diesem Kontrakt intelligent. Statt auf seine Rechte an geistigem Eigentum zu pochen, denkt er taktisch und orientiert sich an den Gegebenheiten und Mechanismen des Literaturbetriebs. Auf Hettners Frage, ob er in Das moderne Drama als Urheber des Zitates genannt werden wolle, antwortet er folgendermaßen:

"Was die Erwähnung meines geringen Namens betrifft, so ist dieselbe bedenklich; doch, vorausgesetzt, daß Sie die Haltbarkeit meiner brieflichen Expektorationen gewiß wohl erwogen und dieselben, wo es nötig, purifiziert haben, mag die Sache immerhin bleiben, da man, offen und ehrlich gesagt, nicht wissen kann, welchem einflußreichen Esel da oder dort dergleichen nützlich in die Nase sticht." (20.9.1851; GB 1, 366) 